\title{
Effects of Commercial Isotonic Sports Drinks during Intermittent Exertion
}

\author{
Sebastian Zart*, Michael Fröhlich \\ Department of Sport Science, Technische Universität Kaiserslautern, Erwin-Schrödinger-Straße 57, 67663 Kaiserslautern, Germany \\ Corresponding Author: Sebastian Zart, E-mail: zart@sowi.uni-kl.de
}

\section{ARTICLE INFO}

Article history

Received: November 02, 2018

Accepted: January 15, 2019

Published: January 31, 2019

Volume: 7 Issue: 1

Conflicts of interest: None

Funding: None

\begin{abstract}
Background: Carbohydrate-electrolyte drinks support performance and recovery during athletic activities. The impact of these isotonic drinks is usually verified by means of placebos without energy. Objective: We checked the extent to which commercial sports drinks may be superior to a syrup-water mixture, similar in calorific value, during an intermittent exertion. Method: In a cross-sectional study, three homogeneously parallelized groups, including a total of 35 test subjects, performed full-strain endurance and speed tests $(5,000 \mathrm{~m}, 3,000 \mathrm{~m}, 1,500 \mathrm{~m}, 800 \mathrm{~m}$, $400 \mathrm{~m}$, and $200 \mathrm{~m})$. During the rest intervals, isocaloric drinks with the same $\mathrm{CHO}(6,66-7,0 \mathrm{~g})$, but different sugar (ISO1: 2,46 g; ISO2: 5,6 g; syrup: 6,7 g) and electrolyte content were given in a randomized way. The parameters of running performance, body weight, rating of perceived exertion, heart rate, and blood lactate concentration were analyzed. Results: Over the distances $(p \geq 0.10)$, the results did not show any ergogenic effect of the isotonic drinks in comparison with the syrup-water mixture. There were also no significant differences in terms of rates of perceived exertion $(p \geq 0.26)$ and the physiological parameters of heart rate $(p \geq 0.30)$ and blood lactate ( $\mathrm{p} \geq 0.18$ ) among the groups. Conclusion: During intermittent and repetitive exertion below 30 minutes, homemade energy drinks exhibited the same effects as commercial sports drinks.
\end{abstract}

Key words: Running, Athletic Performance, Physical Exertion, Physical Endurance, Dietary Supplements, Dietary Carbohydrates

\section{INTRODUCTION}

Considering the large number of competitions and intensified training loads, maintaining and restoring performance in intermittent phases of exertion by means of dietary intake is a key factor (Jeukendrup \& Gleeson, 2010). The administration of carbohydrate-containing sports drinks has positive effects on performance or recovery during athletic exertion (Lee et al., 2011). Quicker recovery leads to improved tolerance of intense exertion, enables a larger training scope, and results in overall higher training efficiency (Kreider et al., 2010). Glycogen stores can be exhausted both during several hours of exertion at $60-80 \% \mathrm{VO}_{2} \max$ and after 15-20 minutes high-intensity exertion at 90-130\% $\mathrm{VO}_{2} \max$ (Coyle, 1991).

Systematic reviews and meta-analyses showed that the administration of carbohydrates before, during, and after exertion has a positive effect on physical performance (Colombani et al., 2013; Pöchmüller et al., 2016; Stellingwerff \& Cox, 2014; Vandenbogaerde \& Hopkins, 2011). Burke and Deakin (2015) even report an increase in performance of up to $20 \%$. One book even proved an increase in performance of up to $20 \%$ (Burke \& Deakin, 2015). Meta-analyses documented positive performance effects of up to $6 \%$ and adverse effects of up to $2 \%$ (Vandenbogaerde \& Hopkins, 2011). Performance improvements are particularly seen in exercise du- rations exceeding 70 minutes. Below this threshold, reviews conducted by Colombani et al. (2013) and Pöchmüller et al. (2016) did not report on any ergogenic effects

Referring to the results of individual studies, it can be stated, contrary to the findings of the meta-analyses, that carbohydrate intake, both by rinsing the mouth with (de Ataide e Silva et al., 2014) and ingesting (El-Sayed et al., 1997; Jeukendrup et al., 1997) carbohydrate solutions, improves performance in exercise even below the threshold of $70 \mathrm{~min}$ utes. Further studies also showed ergogenic effects during exercise durations below 30 minutes (Byars et al., 2006; Byars et al., 2010). In addition to the positive effects of carbohydrate intake in continuous loads, it should be pointed out that increases in performance were also demonstrated with intermittent loads (Davis et al., 2000; Nicholas et al., 1995; Patterson \& Gray, 2007; Phillips et al., 2010; Phillips et al., 2012; Welsh et al., 2002). These studies simulated sports-game-like loads (e.g., soccer), mostly via shuttle runs (e.g., Loughborough Intermittent Shuttle Test) followed by an exertion test.

Burke and Deakin (2015) mentions three mechanisms that are responsible for maintaining and improving performance. First, exogenous carbohydrates stabilize or increase the circulating glucose concentration and delay fatigue. Second, exogenous carbohydrates lead to a slower release 
of liver glucose and maintain a high carbohydrate oxidation rate, which is necessary at high exercise intensity. And third, exogenous carbohydrates - especially by rinsing the mouth - can counteract the negative physical, metabolic and thermal afferent signals from the body, which are caused by the load and contribute to central fatigue and inhibition of motor drive to the exercising muscles.

Besides performance increases, physiological changes occurred when carbohydrates were administered. For example, the hormonal balance (e.g., insulin, growth hormone) differed between the test groups in (Utter et al., 2002), as well as the blood lactate level (Pottier et al., 2010) and the oxidation rates of carbohydrates and lipids when exogenous glucose oxidation is compared with and without carbohydrate administration (Jentjens \& Jeukendrup, 2005).

To verify the effects stated, various carbohydrate or carbohydrate-electrolyte solutions and energy-free placebos are used for a comparison of performance or physiological adjustments during athletic exertion. There is less focus on comparisons between commercial isotonic sports drinks and isolated sugar-water solutions in the form of syrup. Due to the fact that many manufacturers are not able to prove their advertised ergogenic effects $(52.8 \%)$ and since commercial interest may not be excluded (84\%), further scientific research is required in order to estimate the effects of isotonic sports drinks under all kinds of conditions (Heneghan et al., 2012).

Tests with commercial sports drinks prove (Newell et al., 2015; Roberts et al., 2012) or disprove (Burke et al., 2005; Coletta et al., 2013; Qin et al., 2017; van Nieuwenhoven et al., 2005) the ergogenic effects. Coombes and Hamilton (2000) concluded in their tests that no isotonic sports drinks currently on the market are superior to any other. The primary objective of this present study therefore is the comparison of two commercial isotonic sports drinks with a sugar-containing syrup in terms of their effectiveness on running time during high-intensity, intermittent athletic exertion. In addition, the behavior of physiological parameters as secondary objective is examined. We hypothesize that the different isocaloric drinks given will not lead to measurable differences in running time, if several Olympic running distances are completed in the form of an intermittent exercise run.

\section{MATERIALS AND METHODS}

\section{Participants and Design of Study}

A total of 35 subjects (27 male and 8 female test persons), with an average age of $23.4 \pm 3.1$ years and an average weight of $73.9 \pm 9.8 \mathrm{~kg}$ participated in this randomized and double-blind cross-sectional study. Participation was voluntary and without financial remuneration. The subjects were informed on the study objectives and gave their written consent to participate in the study. The studies were planned and performed on the basis of the Declaration of Helsinki (World Medical Association, 2013). All participants were runners or practiced sports with a high degree of endurance, such as soccer, basketball, and handball. The sample calculations were performed with $\mathrm{G}^{*}$ Power 3.1.9.2 and an alpha error of 0.05 and a beta error of 0.80 .
A pre-test was executed one week before the exhaustive exercise test. The test persons were distributed double-blind to the three performance-homogeneous groups (ISO1 and ISO2: commercial sports drinks; Placebo: syrup-water mixture) based on the running time over a distance of $1,500 \mathrm{~m}$ in this pre-test. The distance of $1,500 \mathrm{~m}$ was chosen so that the subjects had to run for at least 5 minutes, but a larger proportion is still provided by the anaerobic energy processes.

From the dinner of the previous day until the test, the participants were given an individual nutrition plan. Before the exertion test each participant performed a standardized warm-up protocol. Subsequently, the subjects ran a total of $10.9 \mathrm{~km}$ on a $400 \mathrm{~m}$ tartan running track, sectioned into stages of $5,000 \mathrm{~m}, 3,000 \mathrm{~m}, 1,500 \mathrm{~m}, 800 \mathrm{~m}, 400 \mathrm{~m}$, and $200 \mathrm{~m}$. The subjects ran alone or in small groups with up to 5 people. Breaks of 20 minutes followed each run to ensure sufficient rest for the next exertion. During the breaks, the measurements were carried out and the drinks were administered. After the 20-minute break, the next phase of exertion started. The sequence of stages run was always identical.

\section{Dietary Behavior}

According to Colombani et al. (2013), the test persons should eat and not appear sober for the tests in order to recreate a real life situation. In order to monitor the dietary behavior and carbohydrate intake of the participants, they all received an individual nutrition plan over three meals. The plan was based on the person's total energy requirement, which had been determined applying the Harris-Benedict formula (Burke \& Deakin, 2015) and their physical activity level (James \& Schofield, 1990). The proportionate energy percentage of the total energy requirement for dinner on the previous day, breakfast, and a snack on the day of the test was $25 \%, 25 \%$, and $10 \%$.

\section{Data Capture}

Before the exertion test, the body weight was determined with the participants wearing underwear. After each leg, running time, heart rate (Polar V800, Polar Electro GmbH, Büttelborn, Germany), blood lactate level (Lactate Scout+; SensLab GmbH, Leipzig, Germany), rating of perceived exertion (Borg scale), and body weight (Sanitas SBF 48, Hans Dinslage GmbH, Uttenweiler, Germany) were recorded (Burke et al., 2005, Utter et al., 2002). Immediately after running, the lactate concentration was determined from the hyperaemized earlobe and rating of perceived exertion was queried. The participant was then weighed, wearing underwear, in order to identify possible changes in body weight.

\section{Intervention}

In accordance with the grouping, either an isotonic sports drink with different sugar content (ISO1: Aktiv ${ }^{3}$ ISOTON, Kräuterhaus Sanct Bernhard KG, Bad Ditzenbach, Germany; ISO2: Hydrate \& Perform, Isostar, Revel, France) or a 
Table 1. Drink specifications for $100 \mathrm{ml}$ liquid intake

\begin{tabular}{|c|c|c|c|}
\hline Properties & ISO1 & ISO2 & Placebo \\
\hline Powder/syrup (g/ml) & 7.2 & 8 & 9.2 \\
\hline Calorific value (kcal) & 26.2 & 29.6 & 28 \\
\hline Carbohydrates (g) & 6.66 & 7.0 & 6.8 \\
\hline of which sugar (g) & 2.46 & 5.6 & 6.7 \\
\hline Lipids (g) & 0 & 0 & $<0.4$ \\
\hline Protein (g) & 0 & 0 & $<0.5$ \\
\hline Calcium (mg) & 26.6 & 32.0 & 0 \\
\hline Potassium (mg) & 23.0 & k.A. & 0 \\
\hline Magnesium (mg) & 13.95 & 12.4 & 0 \\
\hline Sodium (mg) & 64.0 & 64.0 & 0 \\
\hline Vitamin B1 (mg) & No data & 0.046 & No data \\
\hline Ingredients & $\begin{array}{l}\text { Maltodextrin, sucrose, acidifier: } \\
\text { citric acid, calcium lactate, } \\
\text { sodium chloride, trimagnesium } \\
\text { citrate, tripotassium citrate, } \\
\text { aroma }\end{array}$ & $\begin{array}{l}\text { Sucrose, glucose syrup, acidifier: } \\
\text { citric acid, sodium citrate, } \\
\text { maltodextrin, calcium phosphate, } \\
\text { natural lemon aroma and other natural } \\
\text { aromas, magnesium carbonate, sodium } \\
\text { chloride, flavor enhancer: potassium } \\
\text { chloride, antioxidant: ascorbic acid, } \\
\text { color: beta carotene, vitamin B1 }\end{array}$ & $\begin{array}{l}\text { Apple juice }(45 \%) \text { made } \\
\text { of apple juice concentrate, } \\
\text { sugar, glucose-fructose } \\
\text { syrup, acidifier: citric acid, } \\
\text { herb aroma }\end{array}$ \\
\hline Manufacturer data & $\begin{array}{l}\text { Before, during exertion; The } \\
\text { optimized combination of } \\
\text { short-chain and medium-chain } \\
\text { carbohydrates contributes to } \\
\text { maintaining the endurance } \\
\text { performance during the phase of } \\
\text { exertion. The minerals replace } \\
\text { the electrolytes excreted by } \\
\text { transpiration }\end{array}$ & $\begin{array}{l}\text { Before, during, after exertion; Ideal } \\
\text { for intense or long exertion }(<2 \mathrm{~h}) \\
\text { and specially recommended for } \\
\text { athletic activity at high temperatures. } \\
\text { Maintains endurance performance } \\
\text { during long-term endurance training. } \\
\text { Improves absorption of water during } \\
\text { physical exertion }\end{array}$ & \\
\hline
\end{tabular}

Note: ISO1: Aktiv ${ }^{3}$ ISOTON; ISO2: Isostar Hydrate \& Perform; Placebo: Yo-Fruit syrup

placebo (Yo-Fruit syrup apple and alp herbs, Eckes-Granini, St. Florian, Austria) was given (Table 1). The exact amount of drink after each stage was $250 \mathrm{ml}$ for each group, and the energy value of the drinks was at a similar level (327.5-370 kcal). The amount of liquid was determined on the basis of the literature. For very intensive and/or intermittent loads, 150-250 ml liquid should be supplied every 10-20 minutes (Raschka \& Ruf, 2015). No standardization of the amount of carbohydrates based on body weight was deliberately made, because there is no evidence that shows a relationship between body weight and oxidation of exogenous carbohydrates (Burke \& Deakin, 2015).

\section{Statistical Analyses}

The raw values from the log sheets and polar clocks were entered into Microsoft Excel 2016 for import into IBM SPSS Statistics 24 . The descriptive statistics are presented by average values, standard deviations, and coefficients of variation. Inferential statistics were calculated after verification of the preconditions of standard distribution (Kolmogorov-Smirnov test) and variance homogeneity (Levene test) by means of variance analysis (ANOVA) with the between-subjects factor "group".

\section{RESULTS}

The applied statistic matching process did not identify differences between the groups in terms of age, height, weight, and the running performance over $1,500 \mathrm{~m}$ in the pre-test condition (Table 2).

\section{Running Time}

Over the 5,000 $\mathrm{m}$ distance, the placebo group was approximately 4 and $18 \mathrm{~s}$ faster than the ISO1 and ISO2 groups, respectively. However, the ISO2 group achieved the fastest time over the 3,000 $\mathrm{m}$ distance and was 12 and $27 \mathrm{~s}$ faster than the ISO1 and placebo groups, respectively. From a distance of $1,500 \mathrm{~m}$, the times varied less than $3 \mathrm{~s}$, i.e. very slightly among the groups (Table 3 ). The comparison of the coefficients of variation also proved that all groups exhibited similar performances over the various stages with a maximum difference of $3.9 \%$. No significant differences were determined among the three groups for the individual stages (all $\mathrm{p} \geq 0.10$ ).

\section{Ratings of Perceived Exertion}

The participants in all three groups perceived the exertion with values between 15 and 18 on the Borg scale for the 
Table 2. Anthropometric specifications and running time in the pre-test of the three groups

\begin{tabular}{lcccc}
\hline Properties & $\begin{array}{c}\text { ISO1 } \\
{[\mathbf{N}=\mathbf{1 2}]}\end{array}$ & $\begin{array}{c}\text { ISO2 } \\
{[\mathbf{N}=\mathbf{1 1}]}\end{array}$ & $\begin{array}{c}\text { Placebo } \\
{[\mathbf{N}=\mathbf{1 2}]}\end{array}$ & $\mathbf{p}$ \\
\hline $\begin{array}{l}\text { Gender } \\
\text { (male/female) }\end{array}$ & $10 / 2$ & $9 / 2$ & $8 / 4$ & \\
Age [yrs] & $23.4 \pm 2.4$ & $23.4 \pm 4.5$ & $23.5 \pm 2.3$ & $\mathrm{p}>0.05$ \\
Height [cm] & $180.2 \pm 6.7$ & $176.6 \pm 7.2$ & $178.3 \pm 9.4$ & $\mathrm{p}>0.05$ \\
Weight [kg] & $75.2 \pm 9.6$ & $74.9 \pm 7.3$ & $71.7 \pm 12.1$ & $\mathrm{p}>0.05$ \\
Time for & $6: 20 \pm 1: 40$ & $6: 20 \pm 1: 35$ & $6: 15 \pm 1: 28$ & $\mathrm{p}>0.05$ \\
$1,500 \mathrm{~m}[\mathrm{~min}]$ & & & & \\
\hline
\end{tabular}

Note: ISO1: Aktiv ${ }^{3}$ ISOTON; ISO2: Isostar Hydrate \& Perform,

Placebo: Yo-Fruit syrup

individual legs. No significant differences in terms of the ratings of perceived exertion were reported by the three groups for any of the distances (all $\mathrm{p} \geq 0.26$ ).

\section{Heart Rate}

Over the distances of 3,000 m, 1,500 m, $400 \mathrm{~m}$, and $200 \mathrm{~m}$, the placebo group exhibited higher average heart rates than the two ISO groups. Compared to the ISO2 group, the placebo group's average heart rate was up to 7 beats/min higher over all distances. Between the two ISO groups, a more distinct difference of 5 beats/min was identified only over the 5,000 $\mathrm{m}$ distance. Apart from that, the values of the ISO2 group were lower at a maximum of 2 beats/min when compared to the ISO1 group. No significant differences in terms of the average heart rate variable were determined among the three groups over all distances (all $\mathrm{p} \geq 0.30$ ).

\section{Blood Lactate Level}

The ISO2 group showed the lowest concentrations of lactate over all distances. The values of the ISO 2 and the placebo groups were at similar levels. In contrast, the lactate values of the ISO1 group were between 0.5 and $2.1 \mathrm{mmol} / 1$ higher over all distances compared to the other groups. Particularly obvious were the high fluctuations in the group-associated coefficients of variation (7.5-69.4\%) and in comparison between the groups (4.3-48.4\%). No significant differences in blood lactate concentrations were determined among the three groups for the individual stages (all $\mathrm{p} \geq 0.18$ ).

\section{Body Weight}

The proportional change in mass between the three groups over all distances did not differ $(\mathrm{p}=0.99)$ and had values in the range between $+0.53 \%$ and $-1.84 \%$ after the complete test phase. No significant differences in terms of the body weight variable (all $\mathrm{p} \geq 0.72$ ) were determined among the three groups over all distances.

\section{DISCUSSION}

The objective of this study was to verify the effect on running performance during intermittent exertion of two commercial isotonic drinks compared with an isocaloric syrup-water mixture. The sports drinks contained mono-, di-, and polysaccharides as well as electrolytes. The syrup-water mixture contained just mono- and disaccharides, and no electrolytes. The results do not prove any performance-enhancing effect of the isotonic drinks in comparison with the syrup-water mixture over all distances all $\mathrm{p} \geq 0.10$. Furthermore, ratings of perceived exertion all $\mathrm{p} \geq 0.26$ and the physiological parameters heart rate all $\mathrm{p} \geq 0.30$ and blood lactate level all $\mathrm{p} \geq 0.18$ did not show any significant differences among the groups.

The identical running performances of the control group and the test group may be explained by the placebo selected. In contrast to other studies, the classical placebo in the form of water was not applied (Davison et al., 2008; Pöchmüller et al., 2016; Rollo \& Williams, 2009). Instead, the control group received a syrup-water mixture supplying the same amount of energy as the isotonic sports drinks. Besides the $65 \%$ share of carbohydrates specified in the nutrition plan, the energy supply of the drinks was adequate for the exertion because a drop in blood sugar levels and thus a considerable decrease in performance were avoided (Pottier et al., 2010). Compared to another study, both the concentration and the amount of liquid were similar (Nassis et al., 1998). The study also showed no differences between the groups (CHO-E and placebo) in terms of performance, although the load was very high and the exertion time to the presented study was twice as long. This result is contrary to studies that described performance enhancements at a load time of more than 70 minutes (Phillips et al., 2010; Pöchmüller et al., 2016).

Even though the degree of exertion among the groups showed similar values on the Borg scale, we need to critically question the extent to which the participants did exert themselves. According to the Borg scale (values $\geq 17$ ), the highest degree of activity that can possibly be maintained is supposed to be performed (Borg, 1982). Looking at the individual data, only between 48.6 and $74.3 \%$ of the subjects showed ratings of perceived exertion of at least 17 over the individual distances. It remains unclear whether the subjects had a false perception of their performance or whether their possible performance maximum was not exploited. A study of repetitive submaximal sprints over 15 seconds at a load of 80-90 $\mathrm{VO}_{2}$ max showed consistent ratings of perceived exertion of 19. However, the time of exertion was significantly longer here (about 111 minutes) (Nassis et al., 1998). In addition, there is a clear difference in the rest time. The intention to ensure a sufficient recovery over longer breaks could have had an effect on ratings of perceived exertion. In addition, a faster recovery by the supply of carbohydrate solutions would be conceivable. A carbohydrate solution (12.5\%) resulted in a faster reduction in blood lactate level and heart rate after only 10 minutes (Khanna \& Manna, 2005). This could also have influenced the ratings of perceived exertion. However, the concentration of the carbohydrate solution after exertion was twice as high as in the present study.

Since the body weight change during exertion was below $2 \%$, the amount of fluid drunk probably prevented a performance-reducing dehydration in all groups. In some cases, 
Table 3. Average group values and standard deviations of running time, rating of perceived exertion, average heart rate, and blood lactate level over the individual stages

\begin{tabular}{|c|c|c|c|c|c|c|c|}
\hline \multirow{2}{*}{$\begin{array}{l}\text { Stages } \\
\text { Running time [s] }\end{array}$} & \multirow[t]{2}{*}{ ISO1 } & \multirow[t]{2}{*}{ ISO2 } & \multirow[t]{2}{*}{ Placebo } & \multirow[t]{2}{*}{$\mathbf{p}$} & \multicolumn{3}{|c|}{$\mathrm{CoV}$} \\
\hline & & & & & ISO1 & ISO2 & Placebo \\
\hline $5,000 \mathrm{~m}$ & $1424.6 \pm 272.8$ & $1438.0 \pm 272.1$ & $1420.0 \pm 215.9$ & 0.99 & 19.1 & 18.9 & 15.2 \\
\hline $3,000 \mathrm{~m}$ & $852.6 \pm 136.5$ & $837.5 \pm 122.6$ & $864.1 \pm 139.5$ & 0.89 & 16.0 & 14.6 & 16.1 \\
\hline $1,500 \mathrm{~m}$ & $389.8 \pm 69.5$ & $389.7 \pm 74.4$ & $390.5 \pm 64.3$ & 1.00 & 17.8 & 19.1 & 16.5 \\
\hline $800 \mathrm{~m}$ & $181.4 \pm 22.7$ & $180.6 \pm 22.6$ & $183.3 \pm 22.9$ & 0.98 & 12.5 & 12.5 & 12.5 \\
\hline $400 \mathrm{~m}$ & $73.0 \pm 18.2$ & $74.1 \pm 18.5$ & $73.0 \pm 18.3$ & 0.98 & 24.9 & 25.0 & 25.1 \\
\hline $200 \mathrm{~m}$ & $30.2 \pm 15.1$ & $32.4 \pm 16.2$ & $33.7 \pm 16.9$ & 0.10 & 50.0 & 50.0 & 50.1 \\
\hline \multicolumn{4}{|c|}{ Perceived exertion [Borg scale 6-20] } & & ISO1 & ISO2 & Placebo \\
\hline $5,000 \mathrm{~m}$ & $16.25 \pm 2.42$ & $16.55 \pm 2.16$ & $17.08 \pm 1.68$ & 0.62 & 14.9 & 13.1 & 9.8 \\
\hline $3,000 \mathrm{~m}$ & $15.33 \pm 2.31$ & $16.64 \pm 2.20$ & $16.58 \pm 1.88$ & 0.26 & 15.1 & 13.2 & 11.3 \\
\hline $1,500 \mathrm{~m}$ & $16.58 \pm 2.19$ & $16.73 \pm 2.33$ & $16.17 \pm 2.25$ & 0.82 & 13.2 & 100.0 & 13.9 \\
\hline $800 \mathrm{~m}$ & $16.75 \pm 2.26$ & $17.18 \pm 2.60$ & $16.33 \pm 2.39$ & 0.70 & 13.5 & 15.1 & 14.6 \\
\hline $400 \mathrm{~m}$ & $17.17 \pm 2.98$ & $17.82 \pm 1.78$ & $17.83 \pm 2.08$ & 0.74 & 17.4 & 10.0 & 11.7 \\
\hline $200 \mathrm{~m}$ & $16.92 \pm 2.64$ & $17.64 \pm 2.11$ & $17.33 \pm 2.46$ & 0.78 & 15.6 & 12.0 & 14.2 \\
\hline \multicolumn{5}{|c|}{ Average heart rate [bpm] } & ISO1 & ISO2 & Placebo \\
\hline Before $5,000 \mathrm{~m}$ & $122.75 \pm 11.27$ & $116.73 \pm 15.92$ & $122.73 \pm 15.25$ & 0.52 & 9.2 & 13.6 & 12.4 \\
\hline $5,000 \mathrm{~m}$ & $180.51 \pm 7.95$ & $175.36 \pm 8.08$ & $180.06 \pm 10.52$ & 0.33 & 4.4 & 4.6 & 5.8 \\
\hline Before $3,000 \mathrm{~m}$ & $124.33 \pm 14.07$ & $115.78 \pm 10.72$ & $126.83 \pm 14.36$ & 0.17 & 11.3 & 9.3 & 11.3 \\
\hline $3,000 \mathrm{~m}$ & $176.91 \pm 10.98$ & $176.25 \pm 6.99$ & $179.39 \pm 8.91$ & 0.69 & 6.2 & 4.0 & 5.0 \\
\hline Before $1,500 \mathrm{~m}$ & $122.75 \pm 16.84$ & $122.44 \pm 7.72$ & $124.42 \pm 11.44$ & 0.93 & 11.3 & 9.3 & 11.3 \\
\hline $1,500 \mathrm{~m}$ & $175.44 \pm 10.73$ & $174.52 \pm 6.26$ & $177.88 \pm 8.32$ & 0.63 & 6.1 & 3.6 & 4.7 \\
\hline Before $800 \mathrm{~m}$ & $125.55 \pm 13.63$ & $116.40 \pm 14.75$ & $124.00 \pm 12.87$ & 0.29 & 10.9 & 12.7 & 10.4 \\
\hline $800 \mathrm{~m}$ & $174.19 \pm 11.67$ & $172.68 \pm 7.07$ & $174.66 \pm 9.37$ & 0.88 & 6.7 & 4.1 & 5.4 \\
\hline Before $400 \mathrm{~m}$ & $129.91 \pm 16.49$ & $124.82 \pm 13.91$ & $130.33 \pm 18.81$ & 0.69 & 12.7 & 11.1 & 14.4 \\
\hline $400 \mathrm{~m}$ & $166.19 \pm 13.74$ & $164.08 \pm 6.70$ & $170.58 \pm 8.14$ & 0.30 & 8.3 & 4.1 & 4.8 \\
\hline Before $200 \mathrm{~m}$ & $132.92 \pm 17.49$ & $126.27 \pm 16.53$ & $136.33 \pm 16.38$ & 0.36 & 13.2 & 13.1 & 12.0 \\
\hline $200 \mathrm{~m}$ & $156.43 \pm 14.68$ & $155.29 \pm 8.10$ & $162.03 \pm 12.78$ & 0.44 & 9.4 & 5.2 & 7.9 \\
\hline \multicolumn{5}{|c|}{ Blood lactate level [mmol/l] } & ISO1 & ISO2 & Placebo \\
\hline At rest & $1.04 \pm 0.28$ & $1.16 \pm 0.36$ & $0.94 \pm 0.17$ & 0.35 & 26.9 & 31.0 & 18.1 \\
\hline $5,000 \mathrm{~m}$ & $7.34 \pm 1.89$ & $5.68 \pm 3.94$ & $5.86 \pm 1.23$ & 0.56 & 25.7 & 69.4 & 21.0 \\
\hline $3,000 \mathrm{~m}$ & $6.92 \pm 3.00$ & $5.04 \pm 2.35$ & $5.22 \pm 0.85$ & 0.38 & 43.4 & 46.6 & 16.3 \\
\hline $1,500 \mathrm{~m}$ & $6.08 \pm 2.01$ & $5.50 \pm 1.81$ & $5.24 \pm 1.95$ & 0.78 & 33.1 & 32.9 & 37.2 \\
\hline $800 \mathrm{~m}$ & $6.96 \pm 2.05$ & $5.66 \pm 1.63$ & $5.90 \pm 2.05$ & 0.54 & 29.5 & 28.8 & 34.7 \\
\hline $400 \mathrm{~m}$ & $8.86 \pm 2.95$ & $6.80 \pm 0.51$ & $6.86 \pm 1.11$ & 0.18 & 33.3 & 7.5 & 16.2 \\
\hline $200 \mathrm{~m}$ & $9.16 \pm 2.96$ & $8.70 \pm 0.96$ & $8.98 \pm 1.75$ & 0.92 & 32.3 & 11.0 & 19.5 \\
\hline \multicolumn{5}{|c|}{ Change in body weight [kg] } & ISO1 & ISO2 & Placebo \\
\hline Initial weight & $74.04 \pm 9.08$ & $74.91 \pm 7.31$ & $71.73 \pm 12.11$ & 0.72 & 12.3 & 9.8 & 16.9 \\
\hline After $5,000 \mathrm{~m}$ & $73.54 \pm 9.04$ & $74.42 \pm 7.21$ & $71.33 \pm 12.07$ & 0.74 & 12.3 & 9.7 & 16.9 \\
\hline After $3,000 \mathrm{~m}$ & $73.36 \pm 8.96$ & $74.23 \pm 7.07$ & $71.12 \pm 11.99$ & 0.73 & 12.2 & 9.5 & 16.9 \\
\hline After $1,500 \mathrm{~m}$ & $73.28 \pm 8.96$ & $74.18 \pm 6.97$ & $71.17 \pm 12.04$ & 0.74 & 12.2 & 9.4 & 16.9 \\
\hline After $800 \mathrm{~m}$ & $73.41 \pm 9.00$ & $74.32 \pm 7.07$ & $71.23 \pm 12.05$ & 0.74 & 12.3 & 9.5 & 16.9 \\
\hline After $400 \mathrm{~m}$ & $73.56 \pm 8.94$ & $74.35 \pm 7.10$ & $71.29 \pm 12.05$ & 0.74 & 12.2 & 9.5 & 16.9 \\
\hline After $200 \mathrm{~m}$ & $73.64 \pm 8.84$ & $74.53 \pm 7.04$ & $71.36 \pm 12.07$ & 0.72 & 12.0 & 9.4 & 16.9 \\
\hline
\end{tabular}


the fluid drunk even exceeded the loss of fluid and led to a slight increase in weight. Due to the mostly cool to moderate temperatures $\left(14-27^{\circ} \mathrm{C}\right)$ on the days of the test, the loss of fluid did not reach the critical range of above $2 \%$. Coyle (2004) was able to prove that under these conditions runners are able to tolerate the loss of fluid determined. As Isostar (ISO2) is specially advertising improved absorption of water during physical activity in high temperatures, it is possible that this drink was not able to show its potential. Fluid absorption basically depends on the carbohydrate content. All drinks had a sugar content of about $7 \%$ and thus met the recommendations for rehydration drinks (Kerksick et al., 2017). Therefore, their influence on fluid delivery can be seen as identical because different sodium amounts showed no differences in fluid delivery (Jeukendrup et al., 2009). Only the type of sugar could have had an influence on energy supply. The higher gastric emptying rate of maltodextrin solutions in comparison with free glucose solutions can result in increased intestinal absorption (Snell et al., 2010). Since all drinks contained a mixture of dissolved carbohydrate, transferability of results is difficult. According to Burke and Deakin (2015), the contained sugars maltodextrin, sucrose, and glucose oxidize at values of up to $1 \mathrm{~g} / \mathrm{min}$ and fructose up to $0.6 \mathrm{~g} / \mathrm{min}$.

Added electrolytes in an isotonic drink are supposed to improve the storage and distribution of fluids that are taken when heavily sweating, thus indirectly optimizing performance (Castell et al., 2015). For example, muscle cramps or reduced blood volume can be prevented. Since the exertion caused a moderate fluid loss, we assume that there was no exceeded deficit in the electrolyte balance, and therefore no ergogenic effect is to be expected through carbohydrate-electrolyte solutions. In this case, the level of blood sugar might be more influential on the performance (Pottier et al., 2010). Due to the low degree of fluid loss, we do not assume changes in the cardiovascular system, as can be observed in the form of increased heart rates during long-term exertion and severe loss of sweat (Mora-Rodriguez \& Hamouti, 2012). Even if the placebo group exhibited a higher heart rate, studies show that water and saline solutions can have similar effects on the heart rate when administered during exertion (Mora-Rodriguez \& Hamouti, 2012). In addition, further studies showed a reverse behavior and showed higher heart rates for the carbohydrate-electrolyte group compared to the control group (Davison et al., 2008; Nassis et al., 1998). Apparently, the heart rate as a physiological parameter varies greatly between the subjects and the conditions. Differences in the measured blood lactate concentrations may provide evidence of increased work rate or increased muscle glycogenolysis. The Aktiv ${ }^{3}$ group (ISO1) always shows the highest blood lactate levels. At this point, it is impossible to clarify the extent to which this is due to an increased metabolism or just individual fluctuations. Even with an increased work rate, there was no ergogenic effect during running.

The study shows that even a self-mixed drink with the same calorie content as a sports drink can achieve the same results. Thus, a syrup-water mixture is a cost-effective alternative if intermittent loads of up to one hour are carried out.
In addition, the test persons did not complain of discomfort during or after exercise, so that syrup does not represent a strain on the gastrointestinal tract. Physiological and metabolic changes in heart rate and blood lactate due to the syrup used also did not occur.

The results could have been influenced if the given nutritional protocol was not adhered to. Thus, the runners could have experienced different conditions. When recording data in the stadium, the performance is always dependent on the weather conditions. Headwind or a wet track could have hindered maximum performance. In addition to these possible limitations, the subjects should show a willingness to perform. The extent of their willingness cannot be verified. To gain further insight into the effect of carbohydrates in the present protocol, an additional control group should be planned which would receive a liquid without carbohydrates and electrolytes. The design carried out does not reveal whether the carbohydrate intake caused an increase in performance or a delay in fatigue. The supplementation could also have been ineffective in this exercise run. In addition, the effects can vary depending on the individual. Here, a randomized crossover controlled trial would be appropriate. Another point to be viewed critically is the point in time at which the drinks administered might have had an effect. According to Jeukendrup et al. (2009), a minimum of 30 minutes was required after drinking glucose solutions with deuterium oxide (D20) until a high level of D2O could be measured in the blood plasma. In addition, Coyle (2004) states that positive effects of isotonic drinks on heart rate or core body temperature during exertion in hot temperatures may occur only after 40-60 minutes. This means that an ergogenic effect by the drinks could have set in only starting at a distance of 1,500 m. Future studies should use a crossover design to check the effectiveness of isotonic drinks during long and intensive training sessions, plan the first drink intake with sufficient time before exercise and consider a real control group. Furthermore, the running distance and thus the loading time could be extended to produce a load that lasts over 70 minutes and in this way potential effects could be made visible.

\section{CONCLUSION}

We have checked the extent to which commercial sports drinks may be superior to a syrup-water mixture, similar in calorific value, during an intermittent exertion. In summary, considering the lack of differences, we need to state that the selected isotonic sports drinks are not superior to the syrup-water mixture during an intermittent exertion of 60 minutes or $10.9 \mathrm{~km}$. On the other hand, it could be assumed that homemade energy drinks are not inferior to commercial sports drinks and that early and excessive fatigue during training can be prevented in order to achieve maximum training stimuli.

\section{ACKNOWLEDGMENTS}

The authors declare that there are no conflicts of interest or any commercial support. The authors would like to thank 
Luisa Reusch, Jonas Bilan, and Marco Backfisch for their support in data collection, and all study participants for their attendance.

\section{REFERENCES}

Borg, G. A. (1982). Psychophysical bases of perceived exertion. Medicine and Science in Sports and Exercise, 14, 377-381.

Burke, L., \& Deakin, V. (2015). Clinical Sports Nutrition (5 ed.). Australia: McGraw-Hill Education.

Burke, L. M., Wood, C., Pyne, D. B., Telford, D. R., \& Saunders, P. U. (2005). Effect of carbohydrate intake on half-marathon performance of well-trained runners. International Journal of Sport Nutrition and Exercise Metabolism, 15(6), 573-589. doi: https://doi.org/10.1123/ ijsnem.15.6.573.

Byars, A., Greenwood, M., Greenwood, L., \& Simpson, W. K. (2006). The effectiveness of a pre-exercise performance drink (PRX) on indices of maximal cardiorespiratory fitness. Journal of the International Society of Sports Nutrition, 3(1), 56-59. doi:10.1186/1550-2783-3-1-56

Byars, A., Keith, S., Simpson, W., Mooneyhan, A., \& Greenwood, M. (2010). The influence of a pre-exercise sports drink (PRX) on factors related to maximal aerobic performance. Journal of the International Society of Sports Nutrition, 7, 12-12. doi:10.1186/1550-2783-7-12.

Castell, L. M., Stear, S. J., \& Burke, L. M. (2015). Nutritional Supplements in Sport, Exercise and Health: An A-Z Guide. Abingdon: Routledge.

Coletta, A., Thompson, D. L., \& Raynor, H. A. (2013). The influence of commercially-available carbohydrate and carbohydrate-protein supplements on endurance running performance in recreational athletes during a field trial. Journal of the International Society of Sports $\mathrm{Nu}$ trition, 10, 17-17. doi:10.1186/1550-2783-10-17.

Colombani, P. C., Mannhart, C., \& Mettler, S. (2013). Carbohydrates and exercise performance in non-fasted athletes: A systematic review of studies mimicking real-life. Nutrition Journal, 12, 16-16. doi:10.1186/14752891-12-16.

Coombes, J. S., \& Hamilton, K. L. (2000). The effectiveness of commercially available sports drinks. Sports Medicine, 29(3), 181-209. doi: https://doi.org/10.2165/00007256200029030-00004.

Coyle, E. F. (1991). Timing and method of increased carbohydrate intake to cope with heavy training, competition and recovery. Journal of Sports Sciences, 9(sup1), 2952. doi:10.1080/02640419108729865.

Coyle, E. F. (2004). Fluid and fuel intake during exercise. Journal of Sports Sciences, 22(1), 39-55. doi:10.1080/0 264041031000140545.

Davis, J. M., Welsh, R. S., \& Alerson, N. A. (2000). Effects of carbohydrate and chromium ingestion during intermittent high-intensity exercise to fatigue. International Journal of Sport Nutrition and Exercise Metabolism, 10(4), 476-485.

Davison, G. W., McClean, C., Brown, J., Madigan, S., Gamble, D., Trinick, T., \& Duly, E. (2008). The ef- fects of ingesting a carbohydrate-electrolyte beverage 15 minutes prior to high-intensity exercise performance. Research in Sports Medicine, 16(3), 155-166. doi:10.1080/15438620802103155.

de Ataide e Silva, T., Di Cavalcanti Alves de Souza, M. E., de Amorim, J. F., Stathis, C. G., Leandro, C. G., \& Lima-Silva, A. E. (2014). Can carbohydrate mouth rinse improve performance during exercise? A systematic review. Nutrients, 6(1), 1-10. doi:10.3390/nu6010001.

El-Sayed, M. S., Balmer, J., \& Rattu, A. J. M. (1997). Carbohydrate ingestion improves endurance performance during a $1 \mathrm{~h}$ simulated cycling time trial. Journal of Sports Sciences, 15(2), 223-230. doi:10.1080/026404197367506.

Heneghan, C., Howick, J., O’Neill, B., Gill, P. J., Lasserson, D. S., Cohen, D., Thompson, M. (2012). The evidence underpinning sports performance products: a systematic assessment. BMJ Open, 2(4), 1-6. doi:10.1136/bmjopen-2012-001702.

James, W. P. T., \& Schofield, E. C. (1990). Human energy requirements. A manual for planners and nutritionists. Oxford, UK: Oxford Medical Publications under arrangement with FAO.

Jentjens, R., \& Jeukendrup, A. E. (2005). High rates of exogenous carbohydrate oxidation from a mixture of glucose and fructose ingested during prolonged cycling exercise. British Journal of Nutrition, 93(4), 485-492. doi:10.1079/BJN20041368.

Jeukendrup, A., Brouns, F., Wagenmakers, A. J., \& Saris, W. H. (1997). Carbohydrate-electrolyte feedings improve $1 \mathrm{~h}$ time trial cycling performance. International Journal of Sports Medicine, 18(2), 125-129. doi:10.1055/s-2007-972607.

Jeukendrup, A., \& Gleeson, M. (2010). Sport nutrition: an introduction to energy production and performance. Leeds: Human Kinetics.

Jeukendrup, A. E., Currell, K., Clarke, J., Cole, J., \& Blannin, A. K. (2009). Effect of beverage glucose and sodium content on fluid delivery. Nutrition and Metabolism, 6, 9-9. doi:10.1186/1743-7075-6-9.

Kerksick, C. M., Arent, S., Schoenfeld, B. J., Stout, J. R., Campbell, B., Wilborn, C. D., Antonio, J. (2017). International society of sports nutrition position stand: nutrient timing. Journal of the International Society of Sports Nutrition, 14, 1-21. doi:10.1186/s12970-017-0189-4.

Khanna, G. L., \& Manna, I. (2005). Supplementary effect of carbohydrate-electrolyte drink on sports performance, lactate removal \& cardiovascular response of athletes. Indian Journal of Medical Research, 121(5), 665-669.

Kreider, R. B., Wilborn, C. D., Taylor, L., Campbell, B., Almada, A. L., Collins, R., Antonio, J. (2010). ISSN exercise \& sport nutrition review: research \& recommendations. Journal of the International Society of Sports Nutrition, 7, 7-7. doi:10.1186/1550-2783-7-7.

Lee, J. K. W., Nio, A. Q. X., Ang, W. H., Law, L. Y. L., \& Lim, C. L. (2011). Effects of ingesting a sports drink during exercise and recovery on subsequent endurance capacity. European Journal of Sport Science, 11(2), 7786. doi:10.1080/17461391.2010.487115. 
Mora-Rodriguez, R., \& Hamouti, N. (2012). Salt and fluid loading: effects on blood volume and exercise performance. In Acute Topics in Sport Nutrition, 59, 113-119. doi:10.1159/000341945.

Nassis, G. P., Williams, C., \& Chisnall, P. (1998). Effect of a carbohydrate-electrolyte drink on endurance capacity during prolonged intermittent high intensity running. British Journal of Sports Medicine, 32(3), 248-252.

Newell, M. L., Hunter, A. M., Lawrence, C., Tipton, K. D., \& Galloway, S. D. (2015). The Ingestion of 39 or 64 $\mathrm{g}^{*} \mathrm{~h}(-1)$ of Carbohydrate is Equally Effective at Improving Endurance Exercise Performance in Cyclists. International Journal of Sport Nutrition and Exercise Metabolism, 25(3), 285-292. doi:10.1123/ijsnem.2014-0134.

Nicholas, C. W., Williams, C., Lakomy, H. K., Phillips, G., \& Nowitz, A. (1995). Influence of ingesting a carbohydrate-electrolyte solution on endurance capacity during intermittent, high-intensity shuttle running. Journal of Sports Sciences, 13(4), 283-290. doi:10.1080/02640419508732241.

Patterson, S. D., \& Gray, S. C. (2007). Carbohydrate-Gel Supplementation and Endurance Performance During Intermittent High-Intensity Shuttle Running. International Journal of Sport Nutrition and Exercise Metabolism, 17, 445-455.

Phillips, S. M., Turner, A. P., Gray, S., Sanderson, M. F., \& Sproule, J. (2010). Ingesting a 6\% carbohydrate-electrolyte solution improves endurance capacity, but not sprint performance, during intermittent, high-intensity shuttle running in adolescent team games players aged 12-14 years. European Journal of Applied Physiology and Occupational Physiology, 109(5), 811-821. doi:10.1007/s00421-010-1404-z.

Phillips, S. M., Turner, A. P., Sanderson, M. F., \& Sproule, J. (2012). Carbohydrate gel ingestion significantly improves the intermittent endurance capacity, but not sprint performance, of adolescent team games players during a simulated team games protocol. European Journal of Applied Physiology, 112(3), 1133-1141. doi:10.1007/ s00421-011-2067-0.

Pöchmüller, M., Schwingshackl, L., Colombani, P. C., \& Hoffmann, G. (2016). A systematic review and meta-analysis of carbohydrate benefits associated with randomized controlled competition-based performance trials. Journal of the International Society of Sports $\mathrm{Nu}$ trition, 13, 27. doi:10.1186/s12970-016-0139-6.

Pottier, A., Bouckaert, J., Gilis, W., Roels, T., \& Derave, W. (2010). Mouth rinse but not ingestion of a carbohydrate solution improves 1-h cycle time trial performance. Scandinavian Journal of Medicine and Science in Sports, 20(1), 105-111. doi:10.1111/j.1600-0838.2008.00868.x.
Qin, L., Wang, Q. R., Fang, Z. L., Wang, T., Yu, A. Q., Zhou, Y. J., Yi, M. Q. (2017). Effects of Three Commercially Available Sports Drinks on Substrate Metabolism and Subsequent Endurance Performance in a Postprandial State. Nutrients, 9(4). doi:10.3390/nu9040377.

Raschka, C. \& Ruf, S. (2015). [Sports and Nutrition]. Stuttgart: Thieme.

Roberts, J. D., Tarpey, M. D., Kass, L. S., \& Roberts, M. G. (2012). An investigative study into the influence of a commercially available carbohydrate-protein-electrolyte beverage on short term repeated exercise performance. Journal of the International Society of Sports Nutrition, 9, 5-5. doi:10.1186/1550-2783-9-5.

Rollo, I., \& Williams, C. (2009). Influence of ingesting a carbohydrate-electrolyte solution before and during a 1-hr running performance test. International Journal of Sport Nutrition and Exercise Metabolism, 19(6), 645-658.

Snell, P. G., Ward, R., Kandaswami, C., \& Stohs, S. J. (2010). Comparative effects of selected non-caffeinated rehydration sports drinks on short-term performance following moderate dehydration. Journal of the International Society of Sports Nutrition, 7, 28. doi:10.1186/1550-2783-7-28.

Stellingwerff, T., \& Cox, G. R. (2014). Systematic review: Carbohydrate supplementation on exercise performance or capacity of varying durations. Applied Physiology, Nutrition, and Metabolism, 39(9), 998-1011. doi:10.1139/apnm-2014-0027.

Utter, A. C., Kang, J. I. E., Robertson, R. J., Nieman, D. C., Chaloupka, E. C., Suminski, R. R., \& Piccinni, C. R. (2002). Effect of carbohydrate ingestion on ratings of perceived exertion during a marathon. Medicine and Science in Sports and Exercise, 34(11). doi:10.1249/01. MSS.0000035055.01069.5C.

van Nieuwenhoven, M. A., Brouns, F., \& Kovacs, E. M. (2005). The effect of two sports drinks and water on GI complaints and performance during an $18-\mathrm{km}$ run. International Journal of Sports Medicine, 26(4), 281-285. doi:10.1055/s-2004-820931.

Vandenbogaerde, T. J., \& Hopkins, W. G. (2011). Effects of acute carbohydrate supplementation on endurance performance: a meta-analysis. Sports Medicine, 41(9), 773-792. doi:10.2165/11590520-000000000-00000.

Welsh, R. S., Davis, J. M., Burke, J. R., \& Williams, H. G. (2002). Carbohydrates and physical/mental performance during intermittent exercise to fatigue. Medicine and Science in Sports and Exercise, 34(4), 723-731.

World Medical Association. (2013). World medical association declaration of Helsinki: Ethical principles for medical research involving human subjects. Journal of the American Medical Association, 310, 2191-2194. 